\title{
Dynamic cultivation of human stem cells under physiological conditions
}

\author{
Dominik Egger ${ }^{1 *}$, Markus Krammer ${ }^{1}$, Jan Hansmann², Heike Walles ${ }^{2}$, Cornelia Kasper ${ }^{1}$ \\ From 24th European Society for Animal Cell Technology (ESACT) Meeting: C2P2: Cells, Culture, Patients, Products \\ Barcelona, Spain. 31 May - 3 June 2015
}

\begin{abstract}
Background
The development of stable tissue-engineered autologous bone grafts in the field of regenerative medicine is still a challenge. Perfusion bioreactors not only provide continuous nutrition supply and waste removal, but are also suitable for the controlled application of mechanical forces like fluid shear stress. Mechanical loading is known to cause mechanotransductive effects like the induction of differentiation, resulting in enhanced deposition of extracellular matrix [1].
\end{abstract}

\section{Experimental approach}

In our study, we determined the optimal flow rate for the osteogenic differentiation of human adipose-derived mesenchymal stem cells (MSC) by applying fluid shear stress that mimics the physiological environment normally experienced by bone progenitor cells in vivo. For this, we first analyzed the porosity of cell substrates with nanofocus-computed tomography as well as their specific permeability at different flow rates. To investigate the effect of controlled application of physiologic fluid shear stress a flow rate of $0.3 \mathrm{ml} / \mathrm{min}$ was used to cultivate MSC in a self-developed perfusion bioreactor. Cells were seeded on a three-dimensional macro-porous zirconium dioxide ceramic scaffold ( 0.3 .106 cells/scaffold) and cultivated in standard growth medium (GM)or osteogenic differentiation medium (ODM) under normoxic $(21 \%$ O2) or hypoxic $(5 \% \mathrm{O} 2)$ conditions for a period of 21 days. After cultivation cell viability was examined using MTT assay. Furthermore DAPI staining was used to evaluate cell distribution. Glucose consumption and lactate production were monitored and histological stainings

\footnotetext{
* Correspondence: Dominik.egger@boku.ac.at

'Department Biotechnology, University of Natural Resources and Life Sciences, Vienna, 1070, Austria

Full list of author information is available at the end of the article
}

(calcein, alicarin red, Von Kossa) were used to evaluate osteogenic differentiation.

\section{Results}

Flow rates between $0.3-5 \mathrm{ml} / \mathrm{min}$ result in fluid shear stress between $0.01-2.5 \mathrm{~Pa}$ which is in the range of physiologic shear stress bone progenitor cells are subjected to in vivo $(0.3-3 \mathrm{~Pa})$ [2]. Consequently a flow rate of $0.3 \mathrm{ml} / \mathrm{min}$ was used for perfusion culture. Cells cultivated on a 3D scaffold remained viable throughout the whole cultivation period. The viability of cells cultivated under perfusion was considerably higher (6-fold or higher) in comparison to static conditions throughout all conditions with the highest viability observed with cells in osteogenic medium with 5\% O2 (Figure 1.1). Cell distribution was more homogenous under dynamic conditions. Although cells appeared to be denser in osteogenic medium than in standard medium no continuous cell layer was observed in any condition. Glucose consumption and lactate production were considerably higher under perfusion throughout all conditions (Figure 1.2). Cells cultivated at $5 \% \mathrm{O} 2$ consumed more glucose and produced more lactate than under $21 \%$ O2. MSC are known to shift from oxidative phosphorylation to anaerobic glycolysis when cultivated under hypoxic conditions which causes a higher glucose consumption and lactate formation. During osteogenesis MSC rely more on oxidative phosphorylation resulting in a lower glucose consumption than during proliferation [3].Higher viability and elevated glucose metabolism seems to be a consequence of enhanced mass transfer due to perfusion cultivation. Matrix deposition (i.e. extracellular calcium and phosphate) was observed in both osteogenic and growth media. It was found to be strongest under dynamic conditions in osteogenic medium but even in standard growth medium devoid of osteoinductive supplements it was stronger than under static osteoinductive conditions. (Figure 1.3). 




Regarding the matrix deposition no difference was observed between 21\% and 5\% oxygen. Mechanical forces are known to have an impact on a variety of cellular processes such as the differentiation towards different lineages. Since the mineralization of the extracellular matrix is crucial for a tissue engineered construct mechanical forces need to be included into tissue engineering processes.

\section{Conclusion}

Physiologic fluid shear stress together with physiologic oxygen conditions $(5 \% \mathrm{O} 2)$ lead to higher cell viability. 
Furthermore the glucose metabolism is elevated under perfusion due to enhanced mass transfer. The application of fluid shear stress results in a stronger differentiation regarding matrix deposition even in standard growth medium without any osteoinductive supplements. These results underline the positive effects of dynamic cultivation and physiologic oxygen concentration which together mimic in vivo conditions. Consequently other factors like medium composition should be adjusted to be more physiologic and taken into consideration during a tissue engineering process to ensure a physiologic tissue maturation.

\section{Acknowledgements}

Part of this work was performed with financial support of the FFG BRIDGE project "3D Tissue".

\section{Authors' details}

'Department Biotechnology, University of Natural Resources and Life Sciences, Vienna, 1070, Austria. ${ }^{2}$ Chair Tissue Engineering \& Regenerative Medicine, University Hospital Wuerzburg, 97080, Germany.

Published: 14 December 2015

\section{References}

1. Holtorf HL, Jansen JA, Mikos AG: Flow perfusion culture induces the osteoblastic differentiation of marrow stroma cell-scaffold constructs in the absence of dexamethasone. J Biomed Mater Res A 2005, 72:326-334.

2. Weinbaum S, Cowin SC, Zeng Y: A model for the excitation of osteocytes by mechanical loading-induced bone fluid shear stresses. J Biomech 1994, 27:339-360.

3. Sart S, Agathos SN, Li Y: Process engineering of stem cell metabolism for large scale expansion and differentiation in bioreactors. Biochemical Engineering Journal 2014, 84:74-82.

doi:10.1186/1753-6561-9-S9-P68

Cite this article as: Egger et al:: Dynamic cultivation of human stem cells under physiological conditions. BMC Proceedings 2015 9(Suppl 9): P68.

\section{Submit your next manuscript to BioMed Central} and take full advantage of:

- Convenient online submission

- Thorough peer review

- No space constraints or color figure charges

- Immediate publication on acceptance

- Inclusion in PubMed, CAS, Scopus and Google Scholar

- Research which is freely available for redistribution

Submit your manuscript at www.biomedcentral.com/submit 